\title{
REPORT ON AN UNUSUAL CASE OF APLASTIC ANEMIA *
}

\author{
LAWRENCE WELD SMITH, A.B. \\ BOSTON
}

An unusually interesting case of anemia came under observation during the past summer at the Children's Hospital. The results of the rather careful study of the case are presented with the hope that they may be of some value in clearing up the uncertainties which unfortunately surround many of these vague blood conditions. The following is the clinical history in brief, touching on all the points which seem of the slightest diagnostic significance in considering the case.

\section{REPORT OF CASE}

J. K., aged 6 years and 3 months, was admitted April 6.

Birthplace, Middleboro, Mass.; nationality, Russian.

Family History.-The father has been told his left lung is diseased. No family history of syphilis, hemophilia, anemia, etc. Two brothers are living and well.

Personal History.-Full term, normal delivery; breast fed for six months; measles eight months and summer complaint eighteen months prior to admission; subject to colds and sore throat.

Present Illness.-General malaise for the previous two weeks; anorexia; has seemed very weak. His rest has been disturbed by dreams and hallucinations of sight. This latter condition may have been present somewhat for three months. Bowels irregular lately. Urine has been examined and reported negative.

Physical Examination.-Child lying quietly on the table; rather apathetic and cachectic in appearance, with a peculiar sallow complexion, and marked pigmentation, particulariy of the upper eyelids. Eyes are dreamy. He seems to be conscious, but very inanimate. Head, eyes, ears, nose, throat, all negative.

The neck shows a few pea-sized palpable glands.

The thorax is rather flat; no rachitic evidence; sits in a slumping position, with the spine arched.

Heart: Apex diffuse; felt in fourth and fifth spaces; measures 2 by $7 \mathrm{~cm}$; systolic murmur heard over whole precordia, transmitted to axilla; action regular (124), rapid; $\mathrm{A} 2$ and $\mathrm{P} 2$ normal.

Lungs: Dulness on percussion over left apex, with impaired vocal resonance posteriorly; no râles heard.

Abdomen markedly sunken; liver edge just palpable; otherwise negative. Extremities and reflexes all normal.

Skin poorly nourished; dry, sallow, with a peculiar grayish-yellow color suggestive of Addison's disease or pernicious anemia.

Extracts from House Records: April 7: Von Pirquet positive after thirty-six hours for both human and bovine types. Urine, negative. Blood: Red cells, 1,514,000; white cells, 6,200; hemoglobin (Sahli), 40 per cent. Differential Count: Polymorphonuclears, 49 per cent.; lymphocytes, 41 per cent.;

* From the Medical and Pathological Departments of the Children's Hospital. 
basophils, 2 per cent.; myelocytes, 8 per cent. The red cells show some poikilocytosis, anisocytosis and polychromatophilia. There are a few cells which resemble myelocytes, as indicated in the foregoing, and numerous cells which are probably normoblasts. The platelets are about normal in number although possibly somewhat decreased.

April 8, 1918. Feces, negative; show no indigestion of any of the food elements, starch, fat or protein; no ova or parasites seen. Roentgen Ray: Lungs show nothing pathologic.

Treatment.-Iron citrate in ampoule form was given subcutaneously every three or four days.

Diagnosis.-A diagnosis of secondary anemia and mitral regurgitation was made.

Result.-The patient improved noticeably under treatment and observation and was discharged April 26, 1918.

Readmission, July 6, 1918.

Present Illness.-Following discharge home the child was much better for two weeks, and since then has been steadily going down hill. The bowels are constipated; periods of hallucinations increasing, always at night; father has noticed periods of swelling of the lips, nose, head and neck. About a week ago there was a swelling over the forehead over an inch in thickness. It was nonpainful, did not pit on pressure, and disappeared within an hour. His cough has increased. The patient has never been out of Massachusetts; anemia not likely, therefore, to be due to any parasitic infection.

Physical Examination.-Patient is a thin, yellowish-brown pigmented boy, aged about 7 years. The pigmentation is most marked on the back of the neck, the genitals, the umbilicus and the areolae. In general the physical examination is the same as on previous admission. The heart, however, is possibly somewhat enlarged. It measures 2 by $7.5 \mathrm{~cm}$. The impulse is felt outside the nipple line, and is not heaving in nature. The sounds are regular. There is a rough systolic murmur with its point of maximum intensity over the apex, but heard over the entire precordia and transmitted to the axilla. P2 is doubled and accentuated.

Laboratory Findings: July 6: Blood: red blood cells, 762,000; white blood cells, 4,900; hemoglobin (Sahli), 18 per cent.; blood pressure, 115-40. Differential Count: polymorphonuclears, 25 per cent.; lymphocytes, 67 per cent.; large mononuclears, 3 per cent.; eosinophils, 1 per cent.; myelocytes (?), 4 per cent. Smear shows well marked achromia, moderate poikilocytosis, and slight anisocytosis. The lymphocytes are chiefly of the small type. No normoblasts are seen; no plasmodiae noted; no stippling or polychromatophilia.

July 7. Urine, negative; feces, negative.

July 10 . Heart measures 3 by $8 \mathrm{~cm}$.; action regular; slight systolic murmur over whole precordia; slight diastolic murmur at apex; P2 greater than A2; pistol shot and systolic murmur heard in groin (Morse).

July 11. Wassermann negative.

July 12. Up in clothes; feeling better; iron treatment being given.

July 16. Rise in temperature; purpuric areas on front of both thighs.

July 23. Swelling of upper lip without pain or redness; subsided rapidly.

July 24. Blood: red blood cells, 788,000; white blood cells, 3,600; red cells show marked anisocytosis, poikilocytosis and achromia; no nucleated reds seen; no polychromatophilia. Differential Count: Polymorphonuclears, 15 per cent.; mononuclears (mostly lymphocytes), 81 per cent.; transitionals (in previous smear, thought to be myelocytes), 4 per cent.

July 27. Sudden rise in temperature to $105 \mathrm{~F}$., for no apparent cause; ears aching; drums congested and dull; abdomen distended and tympanitic; headache; puffiness about lower lids; somewhat delirious.

July 29. Somewhat better; still has puffiness of face. 
July 31. Slight swelling of left cheek; ulceration at junction of buccal membrane and gum.

August 1. Swelling and ulceration both increased.

August 5. Urine contains a few leukocytes. Blood: red blood cells, 408,000; white blood cells, 5,400.

August 13. Temperature, pulse and respiration all increased. The patient looks poorly, feels very poorly; cough increased; complains of a substernal pain; lungs clear, and no râles heard.

August 15. Blood: red blood cells, 408,000; white blood cells, 4,000; hemoglobin, 10 per cent.

August 17. Cough increased, severe; complains of pain in left ear on coughing; evidently much worse; feels very poorly.

August 18. Severe precordial pain; vomited once.

August 19. Pain much more severe; given morphin (1/16 grain per orem). During the day hecame progressively worse; exhausted; respiration became gasping, and he sank gradually, dying from heart failure at $1: 25 \mathrm{a} . \mathrm{m}$., Aug. 20, 1918.

\section{CLINICAL DISCUSSION}

In brief, the clinical history can be summed up as follows: a boy of 6 who has been apparently well up to the time of the present illness, with the exception of measles eight months previously, comes into the hospital with a history of only two weeks' illness, with no definite symptoms. The clinical picture and the laboratory findings are roughly those of a rather severe secondary anemia, cause unknown. There had been no history of hemorrhage, or of any more recent infection than the measles. He responds temporarily to iron treatment, but soon becomes more anemic and progresses rapidly downhill to fatal exitus. There are very slight purpuric manifestations, and an unexplained swelling of the face, accompanied by high fever. The blood picture, at first suggestive of secondary anemia, becomes more definitely that of an aplastic anemia.

Let us consider the story for a minute from this, the clinical side, before the pathologic evidence is introduced. Gruner's work in 1914 on the biology of the blood cells is perhaps the most satisfactory conception, and more satisfactorily classifies the blood disorders by reference to their point of origin than any of the other modern investigators. In these obscure anemias a diagnosis can only be made by a very careful study of the blood picture, and thorough knowledge of the development of the blood cells is an invaluable aid.

Let us turn to the original blood picture on admission. The other superficial signs of anemia are of little value in differential diagnosis. The pallor, the pigmentation, the anorexia, the disturbed sleep, the irregular bowels, the weakness all fit in equally well with any severe anemia, with the possible exception of the pigmentation, and that we can leave for the moment unexplained. The degree of anemia even at this time is extreme. A hemoglobin of 40 per cent. and a red count of a million and a half in a boy of 6 is seldom noted with a history of 
only two weeks' duration. The differential white count shows a beginning relative lymphocytosis and a drop in the leukocytic proportion. In a child of 6 this is less definite than it would be in an adult. The presence of a good deal of poikilocytosis, anisocytosis and polychromatophilia is, on the other hand, of very great diagnostic value usually, especially when this is further supported by the presence of numerous normoblasts and possibly a few myelocytes. It is a definite indication of marrow activity, or at least of activity of the hematopoietic organs. It is to be regretted that a few other laboratory tests were not carried out - the vital staining of the red cells, the test for fragility in hypertonic salt solution, the bleeding and coagulation times, the retractility of the clot, etc. - but they would have been of interest rather than of any great value in this particular case. The diagnosis of probable secondary anemia was made at this time chiefly because of the active regeneration of the marrow as evidenced by the rather characteristic blood picture. A primary anemia was considered, but with the lack of megaloblasts and macrocytosis, it was dismissed rather summarily, especially as under the iron treatment and general hygiene he improved so very markedly.

During the next two months he was lost sight of, but on readmission, in an even weaker state than previously, and obviously more anemic, the rather obvious primary anemia diagnosis was uppermost in mind. That this was very probable was borne out by the laboratory findings again. A red count of 700,000, a hemoglobin of only 18 per cent., and an obvious relative lymphocytosis could be accounted for most readily by such a diagnosis, even in the absence of normoblasts. At this time little else could be thought of as a differential. Purpura had to be excluded for there was no evidence of hemorrhage anywhere from any of the mucous membranes or into the skin. There was the differentiation between primary pernicious and primary aplastic anemia to be considered, and other than that there was nothing but that rather vague and indefinite group of atypical purpuras with angioneurotic edema, abdominal pain, etc., which Osler mentioned, and the possibility of an aleukemic phase in a case of an acute leukemia. There was nothing to do but follow the case and watch the changes in the blood picture to confirm the diagnosis. This was accordingly done. Red and white counts were made at frequent intervals, differentials done and every care taken to follow the changes in the blood. Thus an aleukemic phase of a leukemia was easily excluded. Again, a primary pernicious anemia never persists with the absolute lack of marrow activity, so far as we know, which this case exhibited, as demonstrated in the peripheral circulation by the lack of young cell forms. 
Thus, the diagnosis comes down either to aplastic anemia or one of those cases of atypical purpura described by Osler. Purpuric-like petechiae did appear in the thighs. Angioneurotic edema of the face occurred. These were both late symptoms, sufficiently so, it seems, to exclude purpura as a diagnosis. In support of the aplastic anemia diagnosis, then, we have the following points, which seem fairly conclusive from the clinical point of view:

1. The age of the patient -- 6 years - which almost automatically excludes primary pernicious anemia.*

2. The fact that the blood pictures never definitely developed into the characteristic pernicious anemia picture.

3. The rapid course, the onset apparently within two weeks, and the entire clinical course occupying less than five months.

4. The cachetic appearance and possibly the pigmentation.

5. The rather characteristic blood pictures toward the latter part of the disease.

6. The purpuric petechiae, the angioneurotic edema, the fever without obvious infection; all more or less characteristic of aplastic anemia. This, then, is the evidence on which the diagnosis of aplastic anemia was made in this case, and which points rather definitely to the idiopathic nature of the disease. The use of the word idiopathic perhaps calls for an explanation. By it is simply meant in this instance a blood disease with a perfectly definite blood picture, which is apparently primary in nature, or at least which has no obvious cause as a secondary anemia following hemorrhage. We will postpone for the moment the discussion of the relation of this disease to the purpuras or to the other anemias and accept its idiopathic nature and its clinical entity. There is, of course much discussion as to whether there is even such a disease, and if so, whether it is a distinct entity or merely a subdivision of the other primary anemias. And if we accept its existence there is then the much debated point as to whether the aplasia of the marrow is the primary pathologic lesion, or whether the aplasia is secondary to some toxic, possibly hemolytic, agent acting in the peripheral circulation.

Before we consider the case any further, let us pass on to the pathologic findings at necropsy in this case. I will only include those parts of the necropsy which are of interest or of diagnostic value and will dismiss the rest of the findings as briefly as possible. Most of the interest is centered in the bone marrow, the liver, the spleen, the heart and the lungs.

* Morse and Wolbach: Case of Pernicious Anemia in a Boy of Eight, Am. J. Dis. Child. 14:301 (Oct.) 1917. 
Pathologic Findings.-Body: The body is that of a fairly well developed and poorly nourished child, measuring $117 \mathrm{~cm}$. in length. The skin has a marked pallor, but is deeply pigmented, especially on the exposed surfaces, the axillae, the groins and genitalia. The mucous membranes are pale, the conjunctivae practically bloodless.

Peritoneal Cavity: There is almost no fat under the skin or in the abdominal cavity, the mesentery and omentum being nearly devoid of any fat tissue. What fat is present is normal in color. The abdominal viscera are all very pale. The lymph nodes (mesenteric) are not enlarged. The diaphragm is normal. There is no free fluid.

Pleural Cavities: Each pleural cavity contains about 50 c.c. of slightly blood-tinged fluid (blood probably from necropsy incision).

Pericardial Cavity: The pericardial cavity contains about 50 c.c. of a clear straw colored fluid.

Heart: The heart weighs $175 \mathrm{gm}$. It is enlarged, dilated and pale. Under the epicardium there are numerous petechial hemorrhages varying in size from a pinpoint to over $2 \mathrm{~mm}$. On cutting the great vessels of the heart, thin watery blood, apparently under some tension, gushes forth. There are no clots in the great vessels or in the left side of the heart. In the right auricle and its appendage there are a few small dark red elastic recent clots. Under the endocardium of the right ventricle and auricle there are similar petechiae, less numerous. The myocardium presents a markedly mottled appearance, due to transverse opaque yellow lines, especially over the papillary muscles (typical tigroid mottling). The myocardium is extremely pale. A few of the chordae tendinae of the posterior group of papillary muscles appear to be somewhat thickened and shortened. The valves are normal, except the mitral, on the posterior segment of which, near the valve edge, are three small pinhead sized, elevated, pigmented, brownish areas resembling fresh vegetations. The valves measure: tricuspid, $8 \mathrm{~cm}$.; pulmonic, $5 \mathrm{~cm}$; mitral, $7.5 \mathrm{~cm}$.; aortic, $4.5 \mathrm{~cm}$. The right ventricular wall measures $4 \mathrm{~mm}$; the left wall measures $7 \mathrm{~mm}$. in thickness.

Microscopic: The cross section shows a very mottled appearance of degenerated muscle fibers and normal muscle fibers. The degeneration consists of fatty infiltration which is everywhere prominent. The fat is found in drops of varying size, many fairly large, which by special stains is found to be chiefly neutral fat, although some of it is in the form of lipoids. The nuclei show little or no changes. Marked myocardial degeneration with fatty infiltration sums up the situation.

Lungs: The lungs do not collapse on opening the chest. The right lung weighs $250 \mathrm{gm}$; the left $190 \mathrm{gm}$. On the surface of the lungs are several small dark reddish areas about pinhead in size. On the posterior surfaces of both lungs are several larger reddish purple blotches covering one to several lobules. Interspersed with these are a few smaller dark red areas about 0.5 $\mathrm{cm}$. in diameter. These latter feel firm to the touch and are not crepitant like the rest of the lungs. With the exception of these areas the lungs are crepitant throughout. On section of the lung tissue, especially of the right, there exudes a clear serous fluid mixed with air bubbles. There are a few discrete areas of bronchopneumonic spots, dark red with a granular surface and firm to the touch, scattered throughout the posterior portion of both lungs. The vessels are normal. The bronchi are normal. The interlobular lymphatics stand out very prominently.

Microscopic: The lungs for the most part are normal. Areas of bronchopneumonia are present, but they lack the true appearance of a pneumonia, for there is comparatively little leukocytic infiltration. The type cell is the wandering mononuclear leukocyte, although there are some polymorphonuclear cells. The exudate is chiefly serum and fibrin, however. The edema is very noticeable. There are places where the exudate is hemorrhagic in nature. The red cells show acidophilic stippling. A few alveoli have their epithelium completely lacking, but in general there is very little destruction to the lung tissue. 
Liver: The liver weighs $440 \mathrm{gm}$. The surface is smooth and the capsule glistening. There is a marked pallor with a distinct brownish tinge. The cut surface is smooth, moist and of a peculiar golden-brown color. The tissue is fairly firm. It is more opaque than usual. The centers of the lobules appear pale and rather suggestive of fatty degeneration. There is a very definite suggestion of hemosiderin deposit from the peculiar color. The vessels appear normal. The lymphatics are rather prominent.

Microscopic: The liver shows very marked central necrosis, with fatty degeneration and infiltration. Peripherally in the lobules there is tremendous hemosiderin deposit. This is best seen by the potassium ferricyanid blue reaction. The liver cells are undergoing marked necrosis centrally. The nuclei show both karyolysis and pyknosis, the former being very suggestive of glycogen deposit. The cytoplasm of the central liver cells is filled with fat droplets of varying size as seen with Scharlach $R$ and Nile blue sulphate stained specimens. The pigment deposit is very much more marked peripherally in the lobules. It is in rather fine granules and arranged chiefly around the nucleus. The sinusoidal epithelium appears to be normal, although rather distended in places as though edematous. Blood cells are very few in number. The red cells show the acidophilic stippling mentioned previously. In the central veins there are accumulations of fibrin and degenerated red cells. In the portal areas the vessels and the bile ducts appear normal. The lymphatics are all distended and filled with coagulated lymph and what appears to be fibrin (Figs. 1 and 2).

Spleen: The spleen is very small and firm, but rather lax. It weighs $18 \mathrm{gm}$. The surface is practically smooth. The capsule is a little thickened. It is bluish red in color. On section the trabeculae are very prominent and very close together. There is increased resistance to the knife on sectioning the organ. The malpighian corpuscles cannot be distinguished. On section the color is dark red.

Microscopic: The capsule is a little thickened. There is an increase of connective tissue throughout the organ, the trabeculae running in from the capsule, being unusually thickened and prominent. The malpighian corpuscles are the striking feature of the histology. They are very prominent and numerous. They appear to be rather smaller than normal and almost coalescent, there is so little splenic pulp. The type cell is the large lymphocyte which shows a tendency to be polygonal. There are numerous rather larger cells which resemble plasma cells. The centers of the corpuscles are undergoing a very definite necrosis. There are numerous pyknotic polymorphonuclear cells there, a good deal of fibrin and considerable fat deposit, chiefly in the mononuclear cells. These are more or less intimately fused, forming what appear to be large giant cells, reminiscent of tubercles, rather typical of toxic degeneration (Mallory's Textbook of Pathology). (Fig. 3.) There is evident edema, for the cells are very widely separated. The pulp reticulum can be clearly seen. In the meshes are a few cells, but the pulp is very limited in amount. The cells are mostly large lymphocytes, plasma cells, and a very few achromatic reds, many of which are stippled as mentioned before. There is no evidence of cellular activity in the spleen as far as blood formation is concerned.

Bone Marrow: The ribs are small in size. They are very pale and do not show the red pulp shining characteristically through them. On section only a very small amount of pale yellow fatty substance can be squeezed out. The marrow in the upper third of the femur is uniformly pale yellow in color, and fatty. There is the most complete aplasia present..

Microscopic: The bone marrow from the femur shows practically no cellular activity. It is composed of almost nothing but adult fat cells with the usual nerve and blood supply. There are very few blood cells to be found in the parenchyma. Here and there a normoblast is to be seen. A few cells which probably are myelocytes can be found. No giant cells are 
noted. There are no definite islands of blood cell formation, simply groups of a few cells scattered through the fat tissue. Practically all types of cells can be found with diligent search, but they are very few. In one place several arteries and nerves can be noted. One of the arteries shows a partially organized thrombus. The red cells in certain instances show a peculiar acidophilic stippling (Fig. 4).

Kidneys: The kidneys show nothing but a few rather fresh surface infarcts, and on microscopic section, a pathologic amount of fat infiltration.

Adrenals: The adrenals are a little dark in color and show a diminished amount of medullary substance, but this is unquestionably partially if not entirely postmortem change.

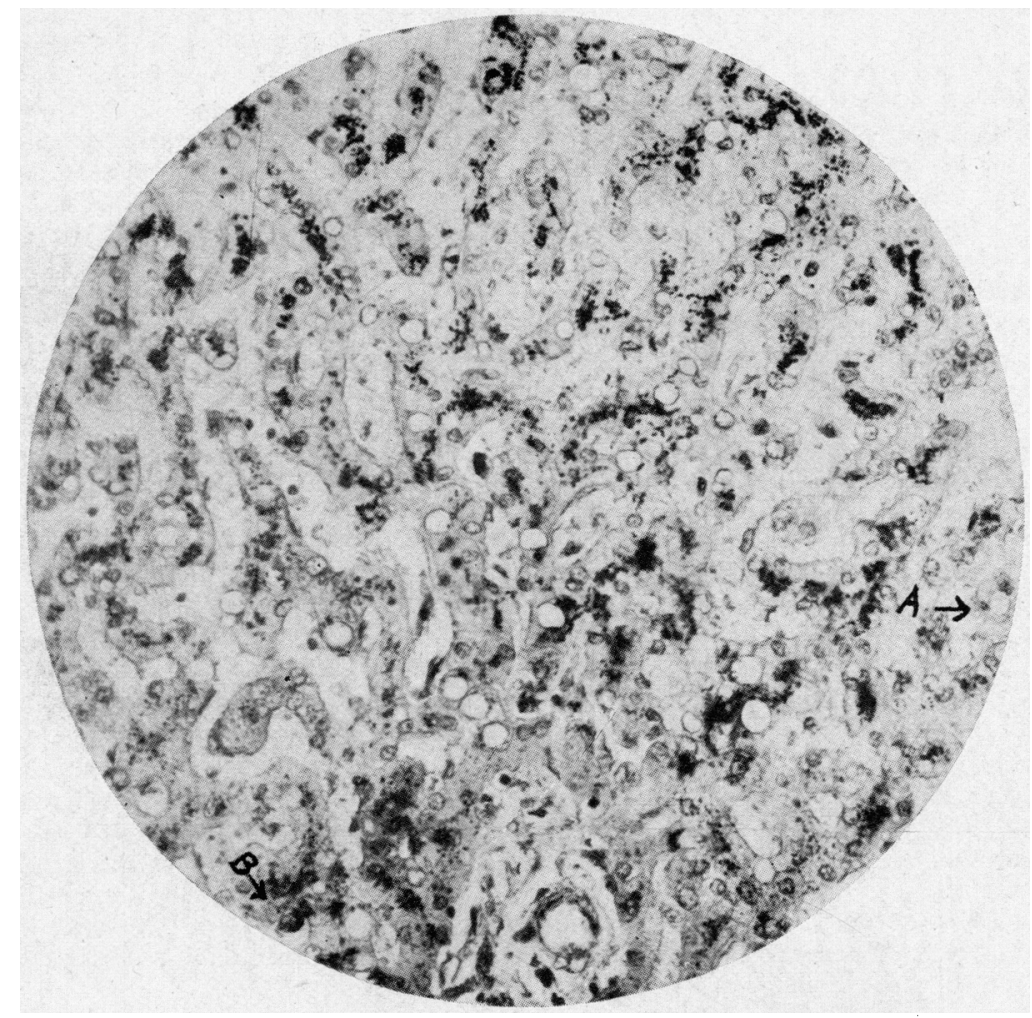

Fig. 1.-Liver. Section illustrates the general distribution of the hemosiderin deposit peripherally in the lobules (Arrow " $\mathrm{B}$ ") and the amount of central necrosis (Arrow "A").

The other organs, the thyroid, the thymus, the gastro-intestinal tract, the pancreas, the gallbladder and ducts, the bladder, the prostate, the testes, the aorta and the blood vessels, all appear to be perfectly normal. The lymph nodes show relatively the same changes noted in the spleen. The skin shows an increase in pigment both in the basal layer of the epithelium and in the connective tissue chromatophores.

Hematology: The blood cells are interesting. The red cells show achromia, and vary with the intensity of their staining reactions. They show acidophilic stippling for the most part. They have a slight tendency toward macrocytosis. There are no embryonic forms in the circulation and very 
few to be found in the marrow. The white cells are peculiarly small, seldom being much larger than the red cells. They are reduced in number. No embryonic forms were found in the circulation, and again, very few in the marrow. Their cytoplasm is very clear, and the characteristic granules are very scarce. No platelets were demonstrated in the sections or in the marrow smears.

\section{PATHOLOGICAI DISCLSSION}

Let us now for a moment consider the case with the additional evidence which the pathologic findings give us. The marrow aplasia is so extreme that there is no hesitancy in making the diagnosis of

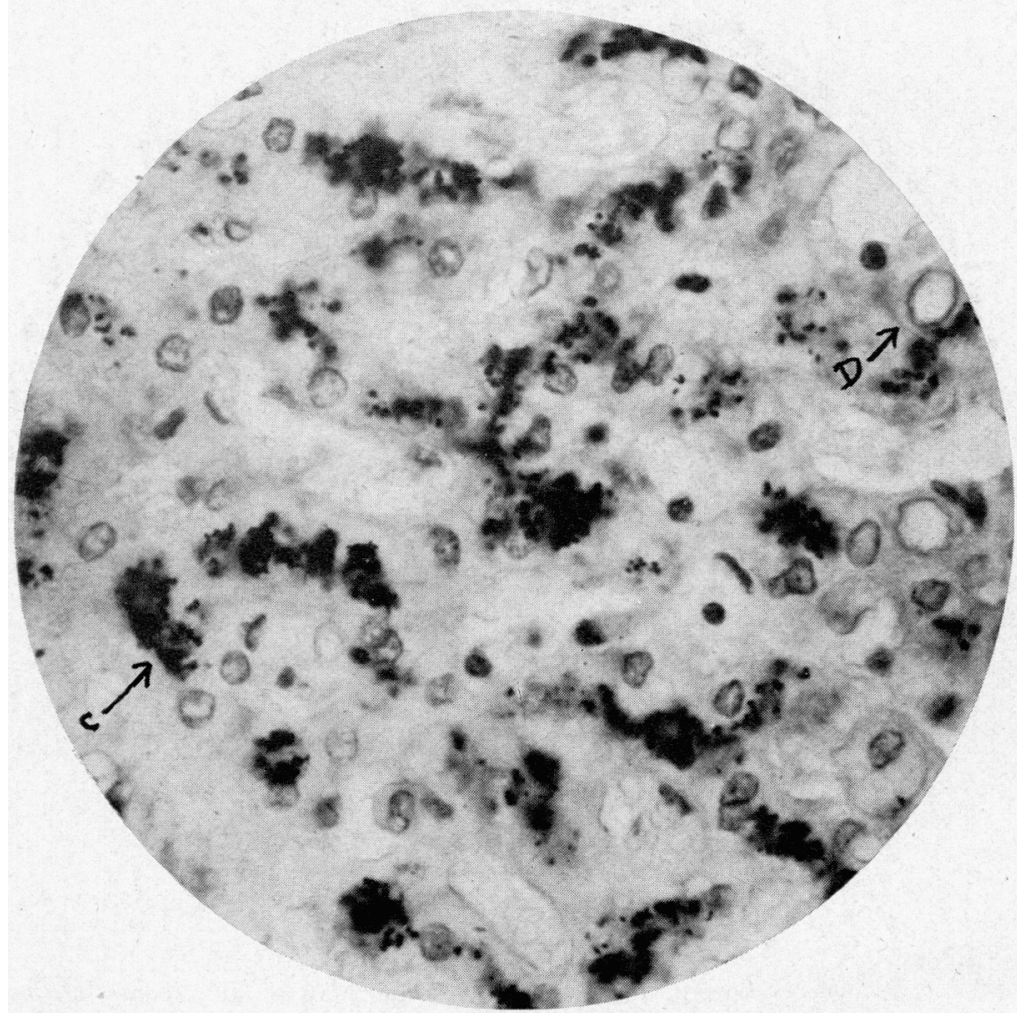

Fig. 2.- Liver. Arrow " $\mathrm{C}$ " shows the arrangement of the hemosiderin in the liver cells, and the apparent glycogen deposit in certain of the nuclei (Arrow "D").

aplastic anemia. Now we turn to seek for the cause, if any is to be found, to account for the condition. The immediate cause of death was a failing circtlation with dilatation of the heart, accompanied by decompensation. The edema of the lungs was partially responsible as well. The primary cause of death, however, goes back a good deal farther than the failing circulation. For those who do not believe in the primary nature of such an anemia - in its idiopathicity - the 
histologic changes in the spleen offer perhaps one solution to the problem. The malpighian corpuscles give very definite evidence of prolonged toxic action such as one sees especially in diphtheria, or in any of the prolonged febrile diseases. It is frequently concomitant with measles. That is perhaps the most obvious answer to the whole story - the prolonged toxic action of the toxin of measles, acting in a cumulative sort of fashion, until the marrow became exhat1sted. Yet

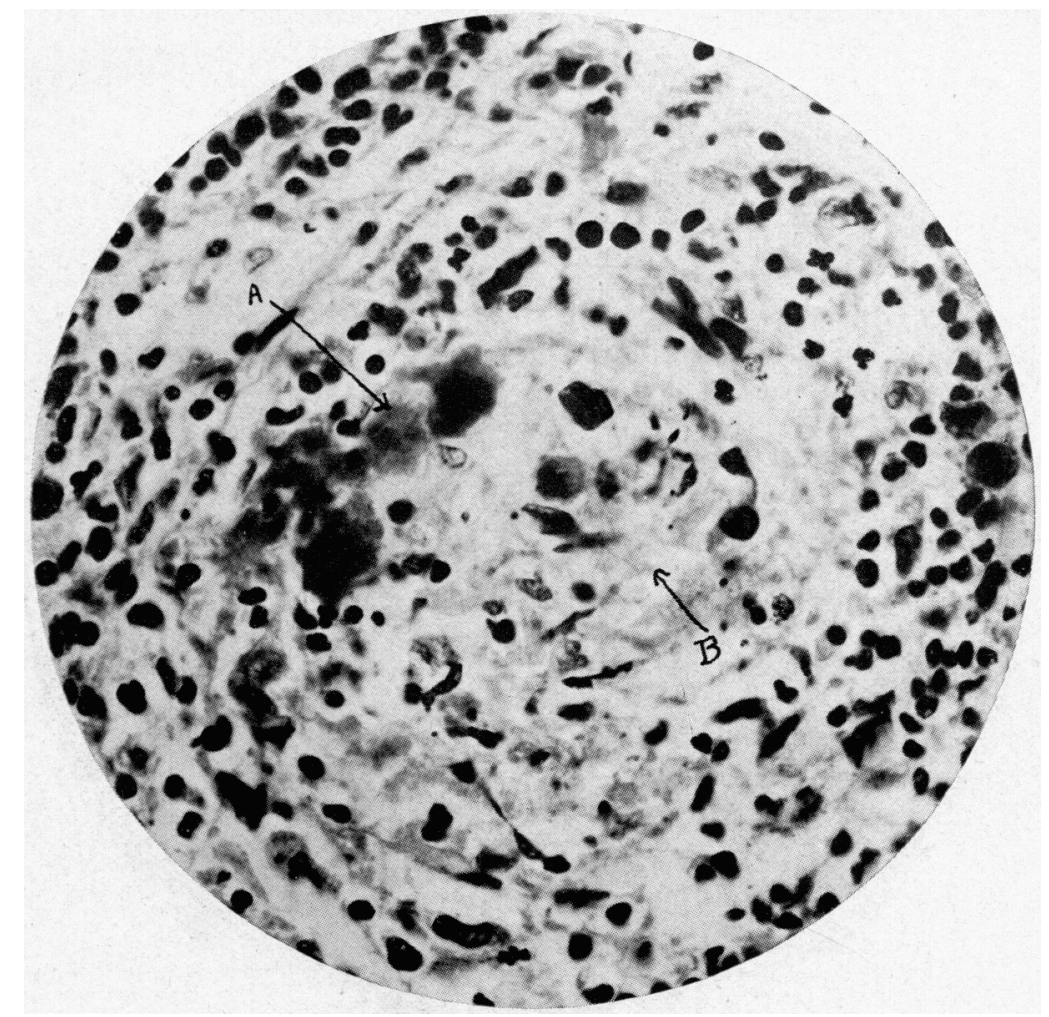

Fig. 3.-Spleen. Section through one of the malpighian corpuscles, illustrating the degrec of toxic degeneration which has occurred. Arrow "A" points toward one of the fused endothelial type cells, with several nuclei. Arrow " $\mathrm{B}$ " indicates the general necrosis present.

we must remember that the child exhibited no symptoms for practically eight months after he had suffered from his attack of measles, which, incidentally, was a rather light case. Personally, from the literature I have found no such prolonged, cumulative action of the toxin of measles, and most certainly in the relatively few cases of aplastic anemia which have been recorded, measles has not in a single instance played the part of causative agent. 
The rest of the pathology gives us absolutely no clue to the cause of the condition. The fatty degeneration of the organs is part of any anemia, merely a question of lack of nutrition. The bone marrow certainly offers no solution to the question. Why? It is merely aplastic, whether primarily or secondarily from exhaustion is impossible to state. That leaves us the liver to consider. There we have a very definite clue in the hemosiderin deposit. In this connection the

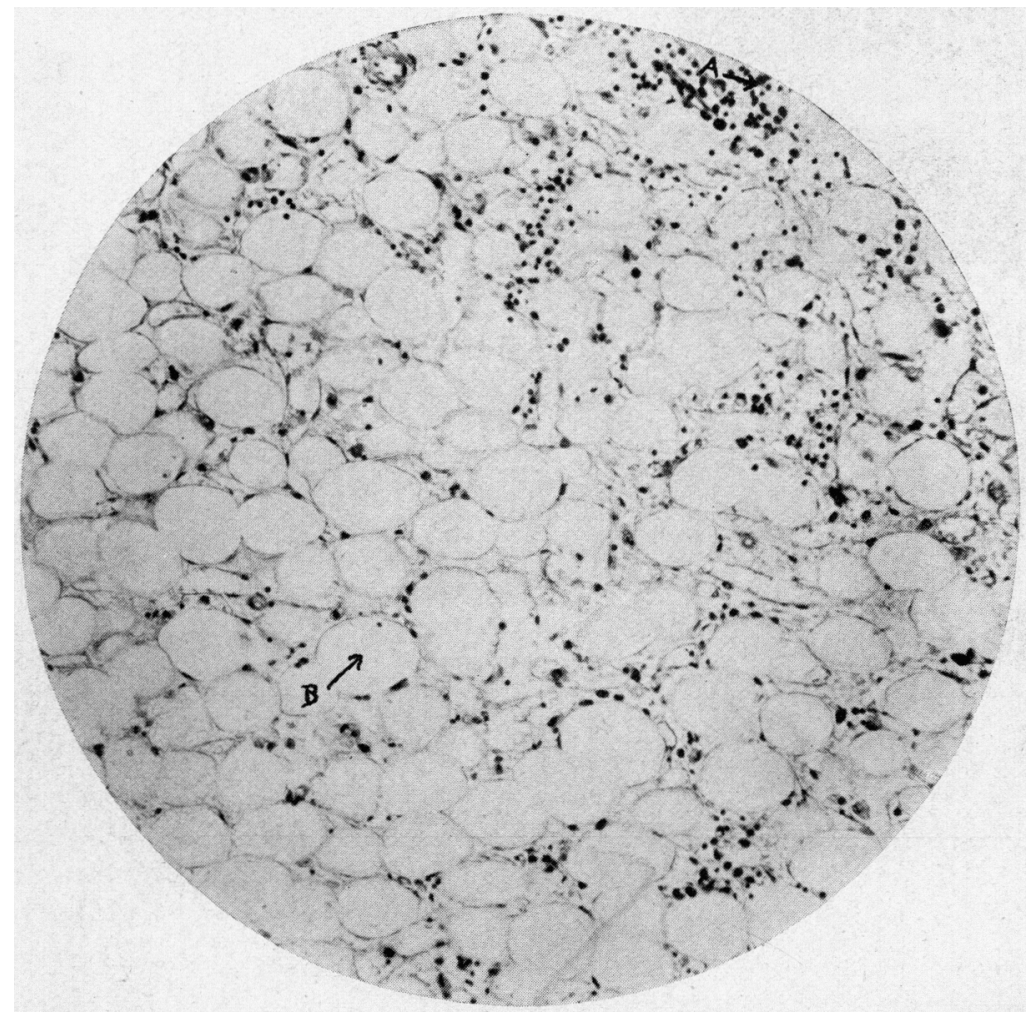

Fig. 4.-Bone marrow from femur. Shows the extreme degree of hypoplasia present. Section is taken from the portion showing greatest activity. Arrow " $\mathrm{A}$ " indicates the nearest approach to island formation of the blood cells. This occurs in the vicinity of a large vessel.

argument is advanced that the presence of iron in any great amount is direct evidence of the hemolytic nature of the disease and its consequent inseparability from pernicious anemia. The amount of iron has even been used as a rough index of the severity of the disease in pernicious anemia and of the rate of red cell destruction. In this connection very interesting experimental work has been done in the injecting of hemoglobin and of hemolytic streptococcic serum, but it 
brings us no nearer a definite conclusion. As toxic hemocytolysis is one of the foremost theories of aplastic anemia, however, this feature of this case seems to be in direct support of this theory. Opposed to this theory is that in which the very presence of hemosiderin in the liver is used as the basis of a differential diagnosis from pernicious anemia and the other hemolytic anemias. It is to be regretted that the pathology in these cases has been so incomplete, for unquestionably the ultimate classification will be on some sort of pathologic basis.

In this case, however, from the clinical history and from the pathologic findings there was no hesitancy in making the diagnosis of aplastic anemia. An acute aplasia of the marrow with severe secondary anemic changes throughout the organs of the body were indisputable evidences. The case seemed to be of more than passing interest, and as the eventual solution of the problem depends on just such fragmentary bits of evidence, it seemed worth while to present the main features in the hope that they may be of some value in that final solution.

\section{LITERATURE AND GENERAL DISCUSSION}

Aplastic anemia is still such an indefinite and vague form of blood disorder that it is interesting to review the literature, and discuss some of the theories which have developed since the condition was first recognized and described by Ehrlich in 1888. Since that time I have been able to find sixty-four cases which have been reported as such. That carries the literature up to December, 1918. Many of those cases are most certainly typical, several others are most questionable, and two or three very definitely present features which seem to exclude them from the classification as it now stands. Many of them present merely the clinical side and have no pathologic findings; these we have to consider very doubtful, as I will show later. Others have very incomplete pathologic findings. That is to be regretted from the scientific point of view, but is of no importance from the diagnostic standpoint.

In 1908 Cabot presented twenty-four cases which he had collected from the literature and deemed authentic. He also mentioned eleven other cases which he rejected from his list as being too atypical or incomplete to be included. This reviews very completely the cases from the time the disease was recognized as a clinical entity by Ehrlich.

In 1911 Hirschfeld presented a new list of forty-four cases which he had collected, which included three of those that Cabot had rejected and twelve which had been included. He also presented a case of his own which was very interesting.

In 1914 Musser published the account of a case which had come under his observation, but which did not come to necropsy for con- 
firmation of the diagnosis. He concluded that it followed the clinical course of the disease accurately enough to fall into that category. His work is particularly of value, not so much because of his case, which, unfortunately, cannot be considered perfectly conclusive without necropsy findings, but because of the résumé he gives of the work since 1908, including the more recent theories, and an excellent bibliography. In that same year Heuber came out with another valuable contribution, and he was followed in 1915 with another memorable article by Weber, both with cases and a brief discussion.

In 1917 Minot brought out a paper which has thrown rather a new light on the subject. He makes the rather obvious but previously disregarded similarity of the blood pictures and clinical symptoms of aplastic anemia and purpura hemorrhagica the basis of a new classification. This has opened a new field of thought, and while it may be the clue that will lead to the eventual solution of the problem, at present it certainly tends to make the subject still more confused. Other than these papers, there has been no apparent effort to collect the literature, and one of the chief purposes of this paper is to bring it as nearly up to date as possible. Since 1914, of course, there have been geographical limitations to the current periodicals, but there have been several cases of indisputable diagnosis which have been published. These are appended in the bibliography at the end of this article.

In a paper of this sort there is unfortunately not space enough to allow of a discussion of all the presented cases. A few cases are so flagrantly secondary to some very definite disturbance - infections, pernicious anemia, etc. - that they can scarcely be included among the recorded cases, especially with the diagnosis unconfirmed by necropsy. Among this latter class may be included the cases presented by Blumer, Senator, Wolff, Stitt, Kurpjeweit, Whipple, Musser and Crummer, in none of which are there any necropsy reports. On the other hand, with the clinical picture as definite as it usually is, with no evidence of marrow activity in the peripheral circulation, possibly one is entitled to make the diagnosis of aplastic anemia. Assuredly the mechanism whereby the cells get into the blood stream is interfered with in some way, or the cells are destroyed as fast as they appear in the circulation. In either event the blood picture clinically is the same and very characteristic. I have made a summary of the sixty-two cases which I have been able to find, in regard to their blood pictures, and possibly that would be of some interest.

It is unfortunate that all the data in each case could not be obtained, but incomplete as it of necessity is, it gives a fairly accurate picture of the severity of the disease, its rapid course, and its low red and white counts. In most of the foregoing cases the marrow showed practically complete aplasia. 
Statistical Analysis of Cases of Aplastic Anemia

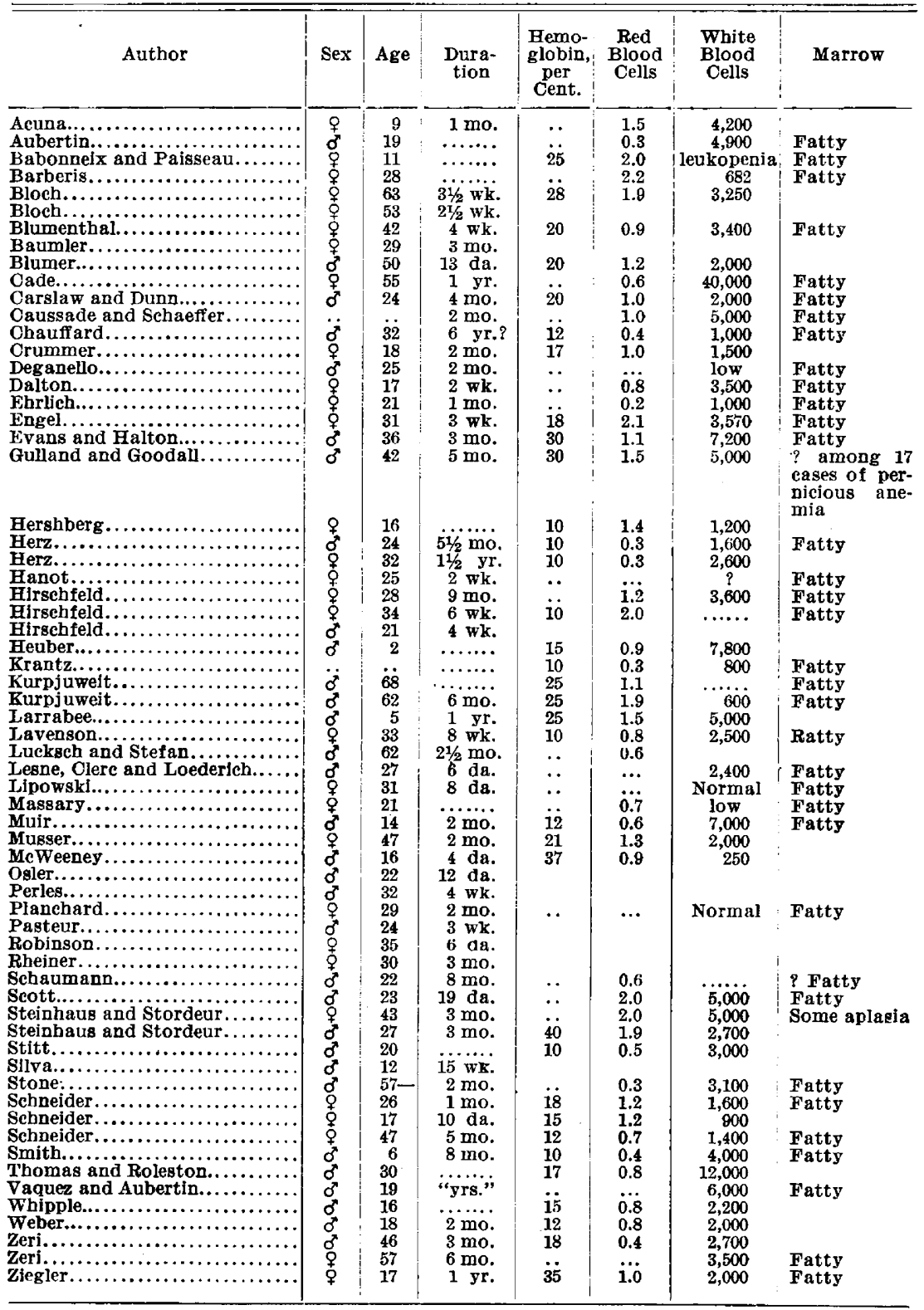


SUMMARY

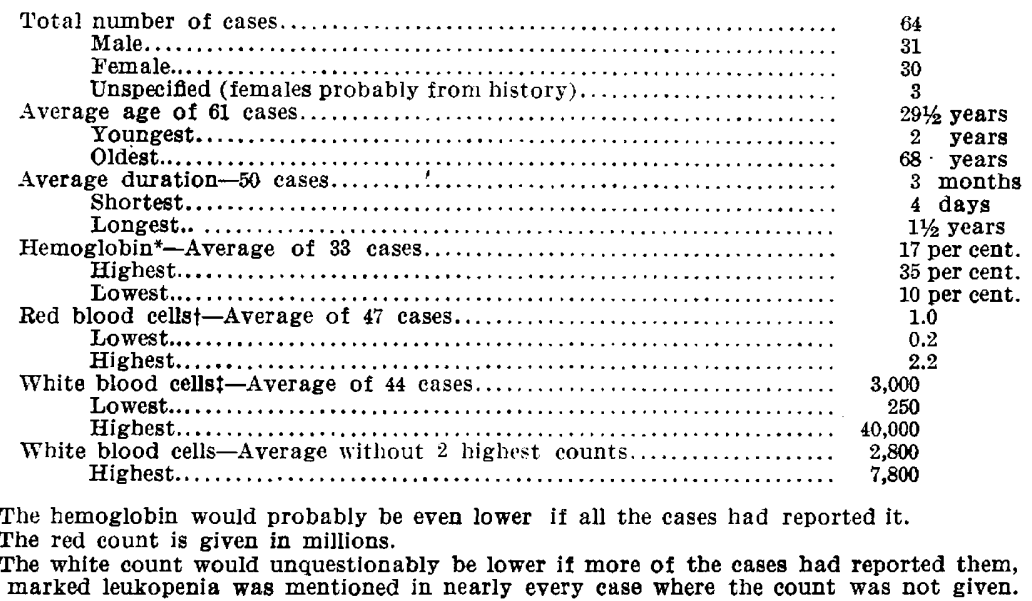

Now let us turn for a moment to the theories concerning aplastic anemia. These may be discussed best perhaps under four headings: first, the etiologic; second, the clinical; third, the pathologic, and fourth, the experimental. First, as to the etiology of aplastic anemia, let us acknowledge defeat at the very start. As yet there is nothing but speculation to advance for the cause or causes of the condition. It is essentially a disease of young adults, occurring chiefly in persons between the ages of 18 and 35. The extremes cited are 2 and 68 years of age. Females are perhaps more susceptible than males - the proportion being about equal in this series of cases, however.

There are numerous theories, all equally tenable. Among them may be mentioned the following: first, that it is the most severe form of pernicious anemia; second, that it is secondary to repeated anemia and therefore a secondary anemia ; third, that it is secondary to some infectious or toxic disease, the toxin acting primarily on the red cells, causing hemolysis; fourth, that it is a primary aplasia of the marrow by some unexplained toxic action on the marrow itself; fifth, that it is dependent on the platelet element of the blood, acted on again either in the marrow or in the circulating peripheral blood stream.

Pappenheim concludes that it is a secondary anemia, secondary to some primary marrow change (which in turn is secondary to some unexplained and unknown toxic change) and has no relation to the ordinary phanerogenetic anemias, or to the so-called primary pernicious anemia, the result of a primary hemolysis.

Lavenson makes the rather broad statement that aplastic anemia is a variety of pernicious anemia, and that the blood picture is due to hemocytolysis plus inactivity of the marrow, which may be caused by the inhibitive action of the same toxins which produce the hemolysis. 
Larrabee after going over the literature both from the clinical and experimental standpoints, in presenting a very unusual case occurring in a boy of 5 concludes that "aplastic anemia is not therefore a disease of itself, but merely a condition which may arise from various causes occurring in secondary anemias, or in pernicious anemia of the destructive type, either as the result of the action of some toxin which destroys the red cells, or from exhaustion of the marrow from overactivity."

Naegli, quoted by Musser, maintains that the relation of aplastic anemia to pernicious anemia is very close, and that the marrow aplasia is due to extraordinarily rapid hemolysis of the red cells, so rapid that the bone marrow cannot keep pace with it and becomes exhausted secondarily. He claims that pernicious anemia is a very constant toxigenetic anemia brought on by toxins from various sources, acting in one of the three following ways: first, by direct hemolysis of the red cells in the peripheral circulation (this has been rather conclusively proved experimentally by McNeil to be unlikely if not impossible); second, by increasing the vulnerability of the red cells to the action of the hemolytic tissues of the body; or third, by stimulating the hemolytic tissues to hyperhemolysis.

Steinhaus and Stordeur, in 1908, published two interesting cases in which everything fits into the usual picture of aplastic anemia except that the marrow was replete with mast cells. They suggest that this may be true in all cases if special stains are used to demonstrate it. This was not found to be so in our case.

Minot lays particular stress on the platelet side of the problem in his comparative studies of aplastic anemia and purpura hemorrhagica, and makes an arbitrary classification of the idiopathic forms of each disease with a large intermediate class which are usually considered as purpura, but which he shows by case evidence to have the pathology of aplastic anemia with the symptoms of purpura. He also differentiates very carefully between the true idiopathic aplastic anemia and the aplasia in other anemias which occurs secondarily to some infection or toxemia, and can more accurately be compared to the experimental aplasia from benzol poisoning. Other points of interest which he makes are those in relation to the clotting of the blood, which in idiopathic aplastic anemia is not very much delayed, but which in coagulating fails to retract in the usual way. His conclusions based on the hemolytic action of the cells in hypotonic salt solution are in general the same as those advanced by McNeil and Hill. The bleeding time is very much increased. This is an important means of differential from cases of hemophilia. 
These various views I merely mention to show the difficulties associated with the solving of the problem of etiology.

Fortunately, however, the disease is fairly definite clinically, and not likely to be confused with the other blood disorders, although it may be difficult to differentiate it from purpura hemorrhagica as I have mentioned, or from an aleukemic phase of an acute leukemia, or even from the secondary or pernicious anemias at certain stages in their course. The history will usually clear away those uncertainties. It is characterized by its rapid and progressively fatal course. No cases have been known to recover. Larrabee's case is the only one with a definite remission, and much doubt has been expressed concerning the classification of the case. It has been suggested that it may fall into the group of secondary aplastic anemias following pernicious anemia.

The disease is associated in almost every instance with hemorrhagic manifestations, either as hemoptysis, epistaxis, or purpuric eruption. Often there is fever accompanying it at some period during its course. This may become alarmingly high, but as a rule does not. The skin may or may not show pigmentation, depending a good deal on the rapidity of its course. Another rather constant clinical feature is the cachetic appearance of the patient, who is profoundly anemic and asthenic.

The blood picture is of course the main point of clinical diagnosis. There is usually a tremendous degree of anemia, with the red cells diminished in number to a million or less. The drop may take place so rapidly that within seventy-two hours there may be a fall from two or three million to seven or eight hundred thousand. The hemoglobin is reduced to 10 or 15 per cent. The color index is usually rather low, in contrast to pernicious anemia, although this is not invariably the case, and it may nearly reach one. The white cells are also reduced, and it is interesting to note that it is only the granular leukocytes (the bone marrow derivatives) that are thus diminished, and that there is accordingly a relative lymphocytosis. This is only relative, however, and the count ranges from 800 to 4,000 . The differential often shows the polymorphonuclear cells reduced to 8 or 10 per cent., while the lymphocytes make up the rest, frequently being over 90 per cent.

A feature of the disease is a reduction in the number of platelets. The red cells present show comparatively slight changes beyond a certain amount of achromia. There is relatively little poikilocytosis or anisocytosis, although the cells may tend to be macrocytic. There is rarely any stippling or polychromatophilia, or vital stained cells. This is of course accounted for by the lack of marrow activity. The 
importance of the blood picture is discussed most conclusively, perhaps, by Minot. The distinguishing features of the blood smear other than these are the absolute lack of normoblasts, megaloblasts, myelocytes, myeloblasts, or any other embryonic form of cell. This picture, conclusive as it may seem, unfortunately can usually be observed at some time or other in a severe case of pernicious anemia, so our final diagnosis must be made at necropsy.

An example of this may be cited briefly by outlining a case which came to necropsy at the Peter Bent Brigham Hospital recently. The patient, a strong, well-developed man of 41 , entered the hospital after a gradual increase of rather indefinite symptoms, with hemorrhages, chiefly from the nose. The blood picture gave the impression of an aplastic anemia ; the hemoglobin was down to about 25 per cent., the red count about 2,000,000, and the white count a little under 5,000 with a relative lymphocytosis. There were no young forms, nucleated reds, etc., practically no poikilocytosis or anisocytosis, and very little achromia. At necropsy the ribs and upper third of the femur showed unusual hyperplasia of the marrow.

With such a case in mind, many of those presented have to be accepted only with great reservation, and only those with necropsy findings of an aplastic marrow can be accepted with complete confidence. In the aplastic marrow we find a complete replacement of the normal marrow by ordinary fat tissue. Occasionally there may be a fibrous proliferation as well. The marrow may show reddish areas, but these are under the microscope found to be areas of hemorrhage rather than islands of active marrow. The perfectly typical aplastic marrow, such as was found in our case, is a yellowish white fat color, greasy to the knife, and practically completely aplastic - more accurately perhaps, acute hypoplasia, with no true islands of marrow activity, even lymphoidal. Occasional myelocytes and young red cells can be found scattered here and there through a solid mass of adult fat cells, with a stroma of delicate blood vessels and connective tissue. Steinhaus and Stordeur with the Mastzellen theory have found no other supporters.

A summary of the reported pathology shows that this aplasia is the most constant and important feature diagnostically. Other features which are usually found are those of any anemia. The organs are pale. There is a diminished amount of fat, and what fat is present, both subcutaneous and in the abdomen, is normal in appearance and not the typical "canary" yellow of pernicious anemia. The mesenteric lymph nodes are very frequently enlarged, the spleen is apt to be hyperplastic. It seldom undergoes any histologic change other than those of congestion and fibrous proliferation. The liver seems to be 
a variable factor. One school maintains that the liver is usually of a peculiar golden brown color suggestive of fatty degeneration and hemosiderin deposit. The other school as insistently states that no hemosiderin is deposited, and that that is a valuable diagnostic bit of evidence in differentiating it from pernicious anemia. Personally, I am inclined toward the hemosiderin theory after seeing the tremendous quantities present in this case. Other observers have noted a considerable hemosiderin deposit in the other organs, especially the kidneys and the spleen. Edema of the lungs has been a variable feature, being dependent purely on physical laws. Other changes have shown no general characteristics of any great value diagnostically.

The pathology in this disease has been as unsatisfactory as the clinical classification, and is especially conspicuous in most instances by its absence or incompleteness. Eventually, presumably the classification must be based on a pathologic basis, as the kidney lesions, for example, have had to be, and it is to be regretted that so little advance has been made in the past towards its ultimate solution. That is one of the chief reasons for the existence of this paper - that this fragment may be added to the accumulation of facts from which the final story will be told, and therefore no apologies are offered for the rather minute pathologic findings which have been presented.

On the experimental side little can be added to help solve the problem. Numerous investigators by as many methods have injected various toxins, including saponin, benzol, ricin, hemolytic streptococcic serum, hemoglobin, and many others, and have produced anemias, even marrow aplasia, but there is one fundamental difference which consistently recurs - the fact that with the removal of the cause, if the period of toxicity in the severest cases can be bridged over for a short time, the condition improves, showing that no vital changes have been effected in the marrow in spite of the cellular destruction. Therefore, it is fairer, perhaps, to let these cases fall into the orthoplastic type of anemia - those due to some obvious cause, such as infection, neoplasm, repeated hemorrhage, parasites and the like, rather than into the metaplastic type which pernicious anemia represents. It is unfortunate that the experimental work cannot be gone into at greater length, but it does not fall into the scope of such an article as this. There may be some diversity of opinion in regard to the theory just advanced, but all will at least admit that these experimental cases of anemia fall into one of the two classes cited in which there is definite effort on the part of the marrow to regenerate, and with the removal of the cause the regeneration proceeds, and that therefore these experimental cases cannot be included in the true aplastic anemias. In this connection it is interesting to note two fatal 
cases of hemolytic aplastic anemia without the usual accompanying jaundice, resulting from TNT poisoning in the course of the manufacture of munitions.

In spite of all the experimental evidence which has been accumulating in the past few years, and which unquestionably will be the ultimate means of discovering the true etiologic factor of the condition, and in spite of all the clinical findings which after all are fairly similar, no definite cause of the disease has yet been found, and we are rather forced to agree with Larrabee that "aplastic anemia is not therefore a disease of itself, but merely a condition which may arise from various causes."

In conclusion I wish to take this opportunity to thank Dr. John Lovett Morse of the Medical Staff of the Children's Hospital for the privilege of reporting the case and for his interest in it, and Dr. S. Burt Wolbach of the Pathological Department for his invaluable assistance in the study of the pathologic specimens and in the preparation of the photomicrographs.

\section{BIBLIOGRAPHY}

Robinson: Med. Rec. 29:218, 1886.

Baumler: Deutsch. Arch. f. klin. Med. 40:448, 1887.

Planchard: Bull. gén. de thérap. 113:126, 1887.

Ehrlich: Charité-Ann. 13: 1888.

Hanot: Arch. gén. de méd. 23:15, 1889.

Rheiner: Cor.-B1. f. schweiz. Aerzte 20:392, 1890.

Perles: Berl. klin. Wchnschr., 1893, p. 965.

Silva: Riforma med. 10:807, 1894.

Lazarus: Die Anemie, 1897.

Engel: Ztschr. f. klin. Med. 2: 1900.

Muir: Brit. M. J., Sept. 29, 1900.

Lipowski: Deutsch. med. Wchnschr., 1900, p. 341.

Schaumann: Volkmann's Samml. klin. Vortr., 1900, p. 287.

Vaquez and Aubertin: Le reactions sanguin, Paris, 1903, p. 195.

Bloch: Zeigler's Beitr. z. path. Anat. u. z. allg. Path. 24:331, 1903.

Pasteur: Lancet, Lond., Nov. 21, 1903.

Cade :* Bull. méd., Paris, July, 1903.

Hirschfeld: Deutsch. med. Wchnschr. 30:650, 1904.

Chauffard: Bull. Soc. méd. d'hôp. 21:313, 1904.

Senator: Ztschr. f. klin. Med. 54:1, 1904.

Dalton: Tr. Clin. Soc. London 37: 1904.

Evans and Halton: J. A. M. A. 44:1195, 1905.

Zeri: Policlinico 7: 1905.

Lesne, Clerc and Loederich: Bull. Soc. méd. d. hôp. 22:726, 1905.

Blumer: Bull. Johns Hopkins Hosp., 1905, p. 127.

Gulland and Goodall: J. Path. \& Bacteriol., January, 1905.

Wolff: Berl. klin. Wchnschr., 1906.

Lavenson: Tr. Assn. Am. Phíys. 21:307, 1906.

Krantz:* Inaug. Dissert., Zurich, 1906.

Morris: Bull. John Hopkins Hosp., 1907, p. 200.

Stone: Ohio State M. J. 3:243, 1907.

Crummer: J. A. M. A. 59:2080, 1907.

Blumentha1: Arch. d. méd. du coeur 5:184, 1907.

* References not found, but outlined in Hirschfeld's article in 1911. 
Blumenthal and Morawitz: Deutsch. Arch. f. klin. Med., 1907.

Steinhaus and Stordeur: Arch. de méd. exper. 20:805, 1908.

Naegli: Blutkrankheiten und Diagnost., 1908, p. 136.

Cabot: Osler's System of Medicine, 1908.

Osler: Unpublished case, mentioned by Cabot, 1908.

Aubertin: Semaine méd., 1908, p. 337.

Dickson: The Bone Marrow, 1908.

Demassary and Weil: Bull. Soc. méd. d. hôp., 1908.

Barberis:* Riforma med., 1908, No. 31.

Caussade* and Schaeffer: Soc. méd d. hôp., May 29, 1908.

Herz:* Wien. klin. Wchnschr., 1908, No. 39.

Lucksch and Stefanowicz: Folia haematol., 1908, No. 5.

McWeeney: J. Path. and Bacteriol., 1909, p. 142.

French: System of Medicine, 1909.

McNeil: J. Path. and Bacteriol. 15:56, 1909.

Selling: Bull. Johns Hopkins Hosp., 1910, p. 32

Carslaw and Dunn: Glasgow M. J., 1910, p. 331.

Thomas and Rolleston: Brit. M. J. 1: 1910.

Babonneix and Paisseau: Arch. d. mal. du coeur, 1910, No. 10.

Ziegler: Deutsch. Arch. f klin. Med. 99:431, 1910.

Hirschfeld: Folia haemato1. 12:347, 1911.

Stitt: U. S. Naval Bull. 5:345, 1911.

Larrabee: Am. J. M. Sc., 1911, p. 57.

Pappenheim: Folia haematol., 1912.

Turk: Klin. haematol., Wien, 1912.

Scott: J. Path. and Bacteriol. 13:342, 1912.

Whipple: Arch. Int. Med. 12:637, 1913.

Gruner: Biology of Blood Cells, 1914, p. 30.

Musser: Arch. Int. Med. 14:275, 1914.

Weber: Proc. Royal Soc. Med., Lond. 7:179, 1914.

Goodkind: Medical Clinics of Chicago 1:781, 1915.

Heuber: Folia haematol, 1915, p. 347.

Hurwitz: Bull. Johns Hopkins Hosp. 26:235, 1915.

Hill: Arch. Int. Med. 16:809, 1915.

Hurwitz and Drinker: J. Exper. Med. 21:525, 1915.

Gorter: Arch. de méd. d. enf., Oct. 16, 1916.

Sellards and Minot: J. M. Research, 1916, p. 469.

Coles: Clin. J., Lond. 45:177, 1916.

Forger: Arch. de méd. d. enf. 19:525, 1916.

Hershberg: Albany M. Ann., December, 1917.

Minot: Arch. Int. Med. 19:1062, 1917.

Schneider: Am. J. M. Sc., December, 1918. 